\title{
PERFIL E PERCEPÇÕES DOS EGRESSOS DO PROGRAMA DE MESTRADO EM CIÊNCIAS CONTÁBEIS EM UMA UNIVERSIDADE ESTADUAL BRASILEIRA
}

\begin{abstract}
Simone Silva da Cunha Vieira
Doutora em Controladoria e Contabilidade - FEA/USP Professora Adjunta da Faculdade de Administração e Finanças da Universidade do
\end{abstract}

Estado do Rio de Janeiro.

Renato Santiago Quintal Mestrando do Programa de Pós-Graduação em Ciências Contábeis (PPGCC) da Universidade do Estado do Rio de Janeiro e Oficial da Ativa do Corpo de Intendentes da Marinha do Brasil.

Robson Augusto Dainez Condé Mestrando do Programa de Pós-Graduação em Ciências Contábeis (PPGCC) da Universidade do Estado do Rio de Janeiro e Auditor-Fiscal da Secretaria de Fazenda do ES.

Valmir Matos do Carmo Filho Mestrando do Programa de Pós-Graduação em Ciências Contábeis (PPGCC) da Universidade do Estado do Rio de Janeiro e Oficial da Ativa da Força Aérea

Brasileira.

\section{RESUMO}

Este estudo objetiva investigar o perfil dos egressos do Programa de Mestrado em Ciências Contábeis (PPGCC) da Universidade do Estado do Rio de Janeiro (UERJ) e suas percepções acerca das contribuições do PPGCC para suas vidas acadêmica e profissional. A pesquisa quanti-qualitativa contou com um questionário como instrumento de coleta de dados, sendo composto por vinte e sete questões (vinte e seis fechadas e uma aberta, de caráter opcional), destinadas aos egressos do Programa. No período entre 1991 e julho de 2011, foram titulados 322 Mestres em Ciências Contábeis. Para o levantamento de dados, foram enviadas 231 correspondências eletrônicas, no período de 09 a 12 de junho de 2011. Do total de questionários enviados, foi observado o total de 38 respondentes. Após a análise das respostas, foi possível traçar o perfil dos egressos do Programa, no que diz respeito a aspectos como idade, sexo, estado civil (antes e depois da conclusão do curso), formação acadêmica e atuação profissional. Adicionalmente, por meio deste estudo, buscou-se captar a percepção do egresso, muito crítica em determinados momentos, acerca das contribuições do Mestrado para a sua vida acadêmica e profissional.

Palavras-chave: Ensino em Contabilidade; Currículo; Pós-graduação; Egressos. 


\section{ABSTRACT}

This study aims to investigate the profile of graduates of the master's program in accounting Sciences (PPGCC) of Rio de Janeiro State University (UERJ) and their perceptions about the contributions of PPGCC for their academic and professional lives. Qualitative research quanti-qualitative a questionnaire as a data collection instrument, being composed of twenty-seven issues (twenty six closed and an open, optional character), intended for graduates of the program. In the period between 1991 and July 2011, 322 were certificated masters in accounting sciences. For the survey data, electronic mailings were sent, in 231 period 09 to June 12, 2011. Of the total questionnaires sent, noted the total 38 respondents. After the analysis of the responses, it was possible to draw the profile of graduates of the program, with regard to aspects such as age, sex, marital status (before and after the completion of the course), academic and professional performance. Additionally, through this study sought to capture the perception of egress, very critical at certain times, about the contributions of the master for their academic and professional life.

Key-words: Teaching in accounting; Curriculum; Postgraduate studies; Graduates

\section{INTRODUÇÃO}

A representatividade das Instituições de Ensino Superior, principalmente os programas de pós-graduação stricto sensu constitui um indicativo gerador de amplas expectativas, no tocante à pesquisa exploratória, para favorecer o conhecimento desse universo e suas contribuições na vida acadêmica e profissional de seus egressos. Spink (1997, p.165) já destacava que "durante muito tempo o mestrado foi o título mais presente no cenário acadêmico, e a maioria dos cursos eram e continuam sendo de mestrado".

Magalhães (2007) subdivide o gênero "instituição de ensino superior" nas espécies universidades, centros universitários, institutos de ensino e instituições isoladas; e acrescenta que o objetivo principal desses organismos é oferecer à coletividade benefícios de cunho social, cultural, educacional e tecnológico. A existência dessas entidades seja no âmbito público como privado, somente faz algum sentido quando há uma contribuição efetiva para o desenvolvimento da nação.

No presente estudo optou-se como cenário o Programa de Pós-Graduação em Ciências Contábeis (PPGCC) da Universidade do Estado do Rio de Janeiro, possuidor de forte tradição em assuntos afetos ao planejamento e controle das entidades públicas e privadas. 


\section{ADMINISTRAÇÃO DE EMPRESAS EM REVISTA}

Face à importância regional do PPGCC, faz-se necessário um rigoroso mapeamento do perfil e da percepção dos seus parceiros: interno e externo. A pesquisa consiste na identificação do perfil dos egressos do Programa, no que diz respeito aos dados pessoais, formação acadêmica e atuação profissional.

O problema desta pesquisa pode ser anunciado com as seguintes questões: "Qual o perfil dos egressos do Programa de Mestrado em Ciências Contábeis da UERJ? e quais as suas percepções acerca das contribuições do Programa para suas vidas acadêmica e profissional?".

Foi analisado o conjunto dos egressos do Programa de Mestrado em Ciências Contábeis da UERJ, de 1991 a 2011. Analogamente ao estudo conduzido por Ramos et al. (2010), esta pesquisa procurou enfatizar a avaliação interna, tendo como finalidade a identificação de pontos fortes e frágeis do Programa, em especial assuntos afetos à coordenação, planejamento e processo decisório, objetivando possíveis modificações no contexto metodológico para adequação do PPGCC às demandas de mercado e aos avanços das tecnologias de informação e comunicação.

A análise do perfil dos egressos do Mestrado em Ciências Contábeis e o mapeamento desse patrimônio intangível da Universidade evidenciam a relevância da pesquisa. O estudo procura retribuir, em forma de conhecimento produzido, o investimento realizado pela sociedade no corpo discente do Programa, através da disponibilização, sem ônus, de infraestrutura e corpo docente altamente qualificado, trabalhando em prol da produção de conhecimento associado ao saber contábil.

\section{FUNDAMENTAÇÃO TEÓRICA}

Historicamente, a evolução humana sempre esteve associada a comportamentos relacionados às habilidades contábeis como a de administração de haveres; o escambo e a reserva de alimentos para prover a escassez, entre outros. Peleias et al. (2007) afirmam que "a evolução da Contabilidade está associada ao progresso da humanidade". Para corroborar essa informação, os pesquisadores acima citados recorrem aos trabalhos de cinco pensadores, cujos trabalhos afetos à evolução histórica da Contabilidade foram abordados em sua pesquisa. O primeiro foi Melis (1950), que realça que a Contabilidade e "sua principal e mais característica manifestação - a conta - é tão antiga quanto a civilização construída pelos homens. Vlaemminck (1961) estudou o desenvolvimento da Contabilidade ao longo da História, 


\section{ADMINISTRAÇÃO DE EMPRESAS EM REVISTA}

associando o seu crescimento à evolução da Ciência Econômica. Peleias et al. (2007) prosseguem citando ludícibus (2006), que afirma que o crescimento das teorias e práticas contábeis está relacionado ao grau de transformação da sociedade. Sá (1997) recorda que a Contabilidade surgiu com a civilização e não desaparecerá em virtude dela. Por fim, Peleis et al. recordam Schmidt (2000). Ele certifica que, tal qual outras ramificações do conhecimento social, a história da contabilidade não pode ser dissociada do meio social dos seus usuários.

No contexto histórico pós Segunda Guerra Mundial, segundo Vianna e Villela [apud Peleias et al., 2007], surgiu o curso superior em Ciências Contábeis. Peleias et al. (2007) complementam o histórico afirmando que este período foi notadamente marcado pela substituição das importações e pelo desenvolvimento técnicoadministrativo das forças produtivas locais. Esse modelo substitutivo, segundo Silva (2005) notabilizou-se ao longo do processo de desenvolvimento brasileiro, em especial no período após a Revolução de 1930 e a Segunda Guerra Mundial, sendo um dos fenômenos propulsores do capitalismo brasileiro. Os pesquisadores acima citados indicam como marco do surgimento do curso de Ciências Contábeis no Brasil, o Decreto-lei n $7988 / 1945$, seguido pelo Decreto-lei $n^{\circ} 15601 / 1946$, por meio do qual o Estado de São Paulo criou a Faculdade de Ciências Econômicas e Administrativas, precursora da Faculdade de Economia, Administração e Contabilidade da Universidade de São Paulo, primeiro pólo de pesquisa contábil no Brasil.

Peleias et al. (2007) afirmam que de meados da década de 1950 até o início da década de 1960, em função do maciço desenvolvimento econômico brasileiro, caracterizado pelas altas taxas de crescimento do PIB, os perfis profissionais foram se modificando, acompanhados pela correspondente adequação dos currículos dos cursos superiores, inclusive o de Ciências Contábeis acompanhando essa tendência.

Pelo panorama traçado, a partir da década de 1990, o ensino superior de Contabilidade novamente sofreu grandes mudanças, em especial no que tange a conteúdos mínimos; duração dos cursos de graduação; normas para elaboração de currículos e agrupamento de disciplinas em categorias de conhecimento, assegurando requisitos mínimos para o exercício profissional de forma responsável e competente. Em consonância com essas mudanças, as Instituições de Ensino Superior em Ciências Contábeis investiram na qualidade da formação de profissionais docentes e da produção acadêmica, como pontos básicos para atuarem na cátedra da educação 
graduada e pós-graduada. Instituições nacionais, acompanhando a política educacional estrangeira, e diante das exigências para manutenção da qualidade dos cursos de acordo com as determinações legais, passaram a admitir docentes com titulação mínima para efetivação de programas de graduação e pós-graduação.

Martins e Monte (2003) lembram que no início da década de 1970 foi criado o primeiro curso de pós-graduação em Contabilidade do País, na Faculdade de Economia e Administração da Universidade de São Paulo (FEA/USP). Na mesma década, foi fundado o Mestrado em Ciências Contábeis no Instituto Superior de Estudos Contábeis da Fundação Getúlio Vargas (ISEC/FGV), que foi reestruturado e transferido em 1990 para a Faculdade de Administração e Finanças (FAF) da Universidade do Estado do Rio de Janeiro (UERJ). Após a transferência para as novas instalações e adaptação do corpo docente à nova cultura organizacional, o Programa de Mestrado em Ciências Contábeis (PPGCC) da FAF-UERJ adquiriu forte tradição no desenvolvimento de atividades acadêmicas relacionadas ao planejamento e controle das entidades públicas e privadas, em especial nos assuntos afetos ao Controle de Gestão.

Em 1998, foi criado o segundo curso de Mestrado em Ciências Contábeis no estado do Rio de Janeiro, na Faculdade de Administração e Ciências Contábeis (FACC), da Universidade Federal do Rio de Janeiro (UFRJ). Até então, a UERJ era a única Instituição de Ensino Superior (IES) do estado a dispor de um curso de mestrado acadêmico na área.

Atualmente, vários egressos do Programa da UERJ integram o corpo docente do Departamento de Contabilidade da FAF e do próprio PPGCC, além de outras Instituições de Ensino Superior (IES) de âmbito regional e nacional. Conforme dados de 2009, disponíveis no site da Associação Nacional dos Programas de PósGraduação em Ciências Contábeis (ANPCONT), o PPGCC ocupava, naquela ocasião, o segundo lugar no total de mestres titulados, com 292 representantes; atrás somente do Programa de Mestrado da FEA/USP, que formara 479 mestres.

O parceiro interno do Programa de Mestrado da UERJ é o mestrando e o externo é sociedade brasileira, em especial a coletividade do Estado do Rio de Janeiro, composta por entidades públicas e privadas, pessoas físicas ou jurídicas, destinatários do conhecimento científico gerado nessa IES. Os apontamentos 


\section{ADMINISTRAÇÃO DE EMPRESAS EM REVISTA}

realizados por Ramos et al. (2010) corroboram a importância de se realizar o contínuo mapeamento do PPGCC da UERJ.

As pesquisas evidenciam que a avaliação é um elemento primordial na formulação de críticas e na tomada de posição acerca do funcionamento de determinado Programa, no que tange a impactos e resultados, podendo indicar novas demandas, estratégias ou metas a serem perseguidas. Não se podem olvidar as recomendações propostas pela Coordenação de Aperfeiçoamento de Pessoal de Nível Superior (CAPES), por ocasião das avaliações trienalmente realizadas nos Programas de Pós-graduação.

\section{PROCEDIMENTOS METODOLÓGICOS}

Conforme sistema de categorias para análise de dados apresentado por Duarte et al. (2009), esse estudo pode ser classificado como uma pesquisa descritiva, quanti-qualitava. A unidade de análise foi o conjunto dos egressos do Programa de Mestrado em Ciências Contábeis da UERJ, de 1991 a 2011. Para identificar o perfil deles, foi elaborado um questionário com vinte e sete questões (vinte e seis questões fechadas e uma aberta, de caráter opcional) por meio do pacote de aplicativos googledocs. O aplicativo permite a disponibilização de questionário a um grande grupo de destinatários através de um link. No período de nove a doze de junho de 2011 , foram enviadas 231 correspondências eletrônicas aos egressos do Programa. Do total de questionários enviados, apurou-se um total de 38 respondentes, o que representa $16,45 \%$ de egressos que se dispuseram a colaborar com a pesquisa. O questionário baseou-se em reflexões dos autores e em contribuições da pesquisa acerca das Ciências da Saúde realizada por Sá et al. (1999) e dos questionários elaborados por Vieira (2009) e Ramos (2009) em pesquisas afins.

As perguntas foram divididas em três grupos: dados pessoais (idade, sexo e estado civil), informações profissionais (formação profissional, e repercussões profissionais) e percepções (avaliação geral e descritiva, e objetivos do curso). A questão aberta, de caráter opcional, foi inserida no questionário visando incentivar a manifestação livre do respondente sobre suas percepções a respeito do Programa. 


\section{ANÁLISE E DISCUSSÃO DOS RESULTADOS}

A coleta de dados via questionário permitiu o levantamento de informações pessoais, formação profissional, repercussões profissionais proporcionadas pelo mestrado, avaliação sobre o Programa de Pós-Graduação em Ciências Contábeis da UERJ (PGCC), objetivos e avaliação descritiva dos egressos sobre o curso.

\subsection{Dados pessoais}

O primeiro item referente aos dados pessoais dos egressos é a idade atual. A faixa etária compreendida entre 36 a 40 anos corresponde a $26 \%$, sendo considerada a maior taxa de concentração desta amostra. O restante $74 \%$ estão pulverizados entre as faixas iniciais de 26 a 55 anos, destacando-se com $18 \%$ a faixa de 41 a 45 anos.
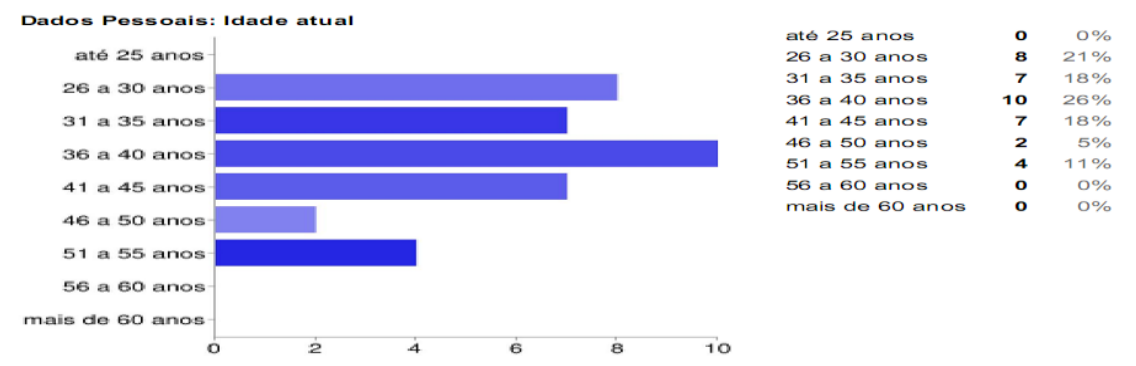

Gráfico 1 - Idade atual dos egressos

O segundo item, conforme Gráfico 2 referente ao gênero dos entrevistados, aponta que $68 \%$ dos egressos são do sexo masculino. Entretanto, o Balanço Socioambiental do CFC (2010) indica um crescimento dos profissionais de contabilidade com registro ativo (registro no CRC e anuidade em dia) do sexo feminino de 4,13\% em relação ao período 2005-2009.

Sexo

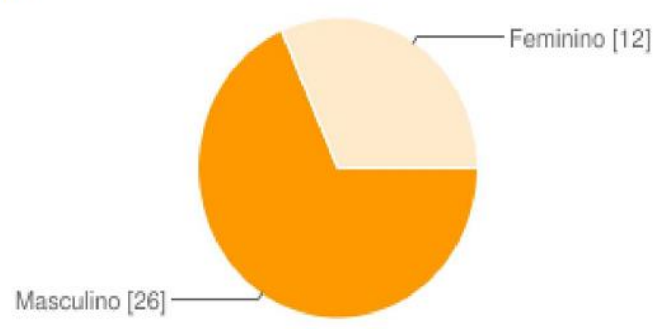

Gráfico 2 - Sexo dos egressos
Masculino $\quad 26 \quad 68 \%$

Feminino $\quad 12 \quad 32 \%$ 


\section{ADMINISTRAÇÃO DE EMPRESAS EM REVISTA}

O estado civil dos egressos (antes, durante e depois da conclusão do curso) é objeto do terceiro item e visa identificar o impacto que a dedicação ao curso poderia exercer na estrutura familiar, em especial no relacionamento conjugal dos pesquisados. Entretanto, os resultados não demonstraram alterações significativas no estado civil dos egressos.

Estado civil ao ingressar no mestrado
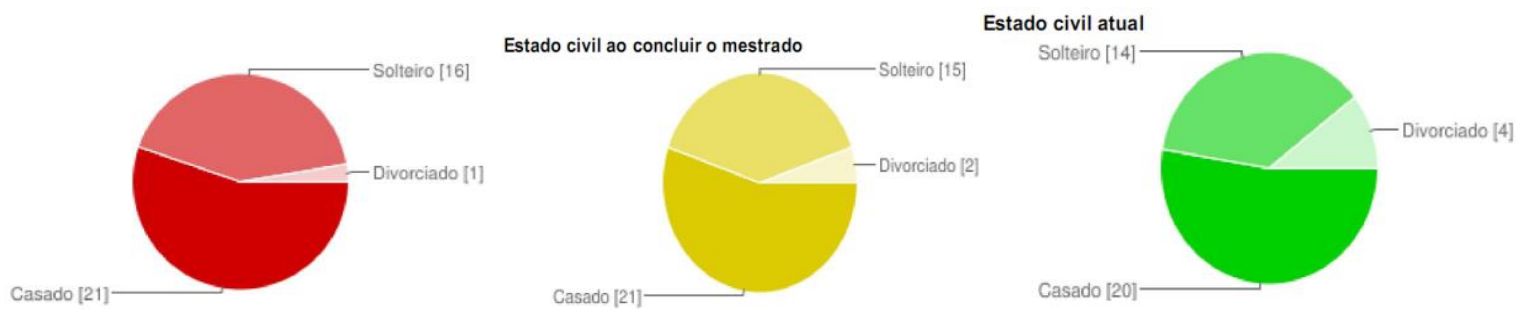

Gráfico 3 - Estado civil dos egressos

A abordagem investigativa do quarto item refere-se à distribuição dos respondentes por períodos de conclusão do Programa. Pode-se verificar que a maioria (69\%) dos respondentes está concentrada no período de tempo compreendido entre 2006 e 2011, ressaltando-se a contribuição dos concludentes do ano de 2009 à pesquisa, ao representar $24 \%$ do total da amostra. O baixo percentual dos respondentes compreendidos entre os concludentes do curso nos anos de 1991 a 2000, pode ter sido influenciado pela desatualização do cadastro dos endereços eletrônicos dos egressos junto à Secretaria do Programa.

Tabela 1 - Distribuição percentual por ano de conclusão do mestrado pelos egressos

\begin{tabular}{|l|l|l|}
\hline Ano de conclusão & Número de egressos respondentes & Percentual \\
\hline 1991 & 1 & $3 \%$ \\
\hline 1995 & 1 & $3 \%$ \\
\hline 1999 & 1 & $3 \%$ \\
\hline 2000 & 1 & $3 \%$ \\
\hline 2002 & 3 & $8 \%$ \\
\hline 2003 & 2 & $5 \%$ \\
\hline 2004 & 2 & $5 \%$ \\
\hline 2005 & 1 & $3 \%$ \\
\hline
\end{tabular}




\section{ADMINISTRAÇÃO DE EMPRESAS EM REVISTA}

\begin{tabular}{|l|l|l|}
\hline 2006 & 3 & $8 \%$ \\
\hline 2007 & 2 & $5 \%$ \\
\hline 2008 & 5 & $13 \%$ \\
\hline 2009 & 9 & $24 \%$ \\
\hline 2010 & 3 & $8 \%$ \\
\hline 2011 & 4 & $11 \%$ \\
\hline Total & 38 & $100 \%$ \\
\hline
\end{tabular}

\subsection{Formação profissional}

O quinto item, conforme Tabela 2 relacionada à formação profissional dos entrevistados, indica uma expressiva demanda pelos candidatos formados em Contabilidade pelo Programa em questão, visto que $89 \%$ dos respondentes são oriundos dessa área de formação.

O PPGCC da UERJ admite em seu processo de seleção candidatos graduados nos cursos de Ciências Contábeis, Administração, Economia ou áreas correlatas. Ao longo da existência do Programa, verifica-se também a participação no curso de Oficiais das Forças Armadas, em especial da Marinha do Brasil. A turma de 2011, composta por dezessete mestrandos, tem em seus quadros três Oficiais oriundos da Marinha do Brasil e um da Força Aérea Brasileira, representando 23,5\% da classe em questão.

A turma de 2011, conforme informações levantadas junto à Secretaria do Programa, apresenta uma maior heterogeneidade em relação às áreas de formação dos discentes, apresentando a seguinte composição: $58 \%$ são formados em Ciências Contábeis, $18 \%$ em Administração e $24 \%$ em outras áreas.

$\begin{array}{lrr}\text { Ciências Contábeis } & \mathbf{3 4} & 89 \% \\ \text { Economia } & \mathbf{1} & 3 \% \\ \text { Administração } & \mathbf{2} & 5 \% \\ \text { Outros } & \mathbf{1} & 3 \%\end{array}$

Tabela 2 - Formação Profissional 


\section{ADMINISTRAÇÃO DE EMPRESAS EM REVISTA}

A abordagem investigativa do sexto item, conforme Gráfico 4 relacionado à atuação profissional dos entrevistados, verifica-se que 47\% dos egressos respondentes trabalham no setor público. O desenvolvimento de pesquisas do PPGCC voltadas para temas da Contabilidade aplicada ao Setor Público e temas afins pode ser um fator determinante para a escolha do Programa por esse determinado público.

A cooperação de longa data estabelecida com a Controladoria Geral do Município do Rio de Janeiro e com a Marinha do Brasil pode contribuir para a manutenção desse percentual. Adicionalmente, observa-se que o Programa em questão é bastante procurado por servidores oriundos dos mais diversos órgãos da Administração Pública, tais como: Secretarias Estaduais de Fazenda; Tribunais de Contas; Banco Central do Brasil; Banco Nacional de Desenvolvimento Econômico e Social; Controladoria Geral da União; Conselho Federal de Contabilidade; Conselho Regional de Contabilidade e Forças Armadas.

A partir do segundo semestre letivo, o PPGCC inicia a preparação dos mestrandos para se tornarem docentes, ao disponibilizar a oportunidade da realização do estágio docente no curso de graduação em Ciências Contábeis da UERJ. Essa característica se reflete nos índices apresentados no gráfico, pois se verifica um equilíbrio entre os respondentes que exercem uma atividade profissional no setor público ou no privado em conjunto com a docência.

Observam-se os seguintes valores percentuais dos egressos que têm duas atividades profissionais: $16 \%$ atuam em atividade de docência e outra atividade remunerada no Setor Público, 16\% atuam em atividade de docência e outra atividade remunerada no Setor Privado; e 18\% atuam somente como docente.

Após a conclusão do Mestrado, o egresso tem a responsabilidade de disseminar o conhecimento adquirido, seja através da realização de pesquisas que venham ao encontro das demandas da sociedade ou por meio da implementação de boas práticas no seu ambiente de trabalho. 


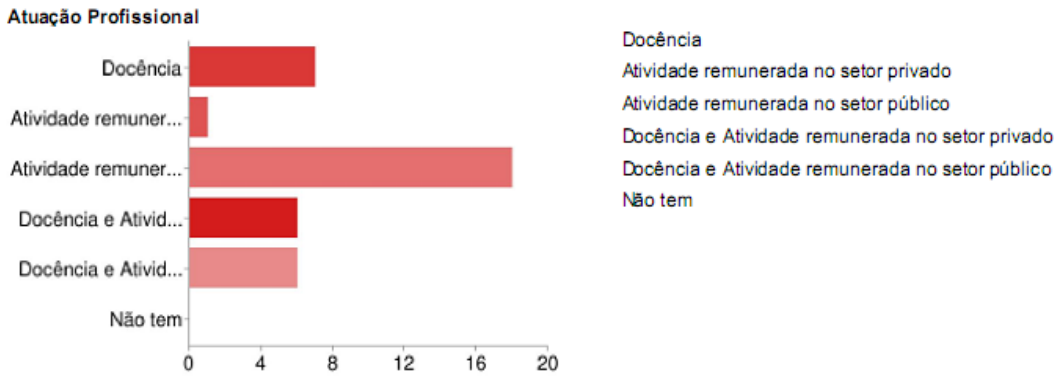

Gráfico 4 - Atuação profissional

\subsection{Repercussões Profissionais do Mestrado}

Antes da realização do Mestrado, 84\% dos respondentes possuíam um único vínculo empregatício; $11 \%$ possuíam mais de um vínculo empregatício; e 5 \% não possuíam vínculo empregatício. Pode-se inferir que os egressos que não possuíam vínculo empregatício tinham dedicação integral ao curso. O fato de não haver aulas todos os dias, viabiliza a participação de alunos em dedicação parcial; embora haja um esforço do Programa para que todos os mestrandos participem das atividades em dedicação integral.

Após a realização do curso, 29\% retornaram ao mesmo vínculo empregatício; $18 \%$ continuaram com mais de um vínculo empregatício; $50 \%$ passaram a ter mais de um vínculo empregatício e 3\% obtiveram o seu primeiro vínculo empregatício. Verificase um aumento da empregabilidade dos egressos do Programa, demonstrado por $42 \%$ dos respondentes.

\subsection{Avaliação Geral do Programa}

A avaliação do currículo do curso pelos entrevistados é objeto do sétimo item, representado pelo Gráfico 5. Foi solicitado aos respondentes que conceituassem vários itens sobre o Programa de Mestrado em Ciências Contábeis da UERJ, utilizando a seguinte escala: 1 - muito ruim; 2- ruim; 3- indiferente; 4 - bom; 5- muito bom. 
No que se refere ao currículo do curso, $13 \%$ dos respondentes consideram o programa muito bom; $50 \%$ avaliaram como bom; $21 \%$ como indiferente; $8 \%$ como ruim; e $8 \%$ como muito ruim.
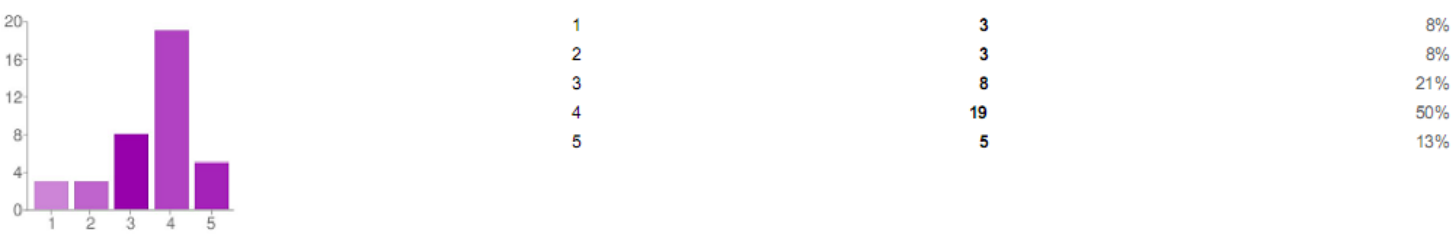

Currículo do curso

Gráfico 5 - Currículo do curso

O oitavo item conforme Gráfico 6 referente à carga horária do curso aponta que $26 \%$ dos respondentes consideraram o programa muito bom; $39 \%$ avaliaram como bom; 18\% como indiferente; 8 \% como ruim; e 8\% como muito ruim.

Em relação ao quesito anteriormente avaliado, o percentual dos respondentes que avaliaram como ruim ou muito ruim permaneceu inalterado (16\%). Houve uma redução em $3 \%$ do percentual de respondentes indiferentes e um aumento de $2 \%$ em relação ao percentual dos respondentes que avaliaram como bom ou muito bom.
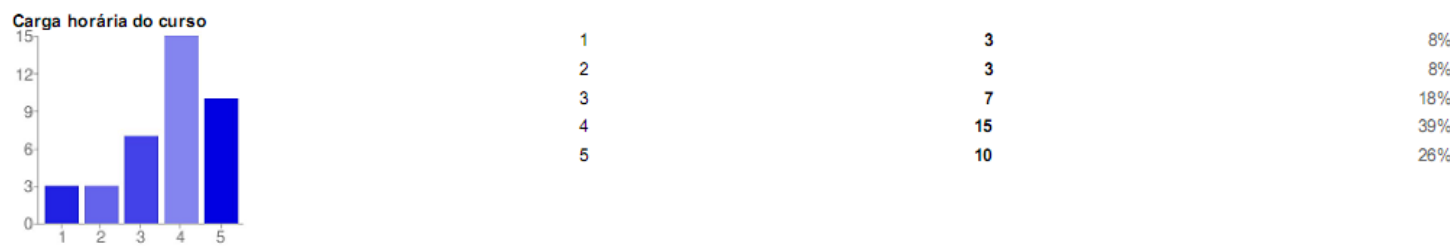

Gráfico 6 - Carga horária do curso

A abordagem investigativa do nono item, conforme Gráfico 7 referente às disciplinas obrigatórias indica que $8 \%$ dos respondentes consideram o programa muito bom; $45 \%$ avaliaram como bom; $21 \%$ como indiferente; $18 \%$ como ruim; e $8 \%$ como muito ruim.
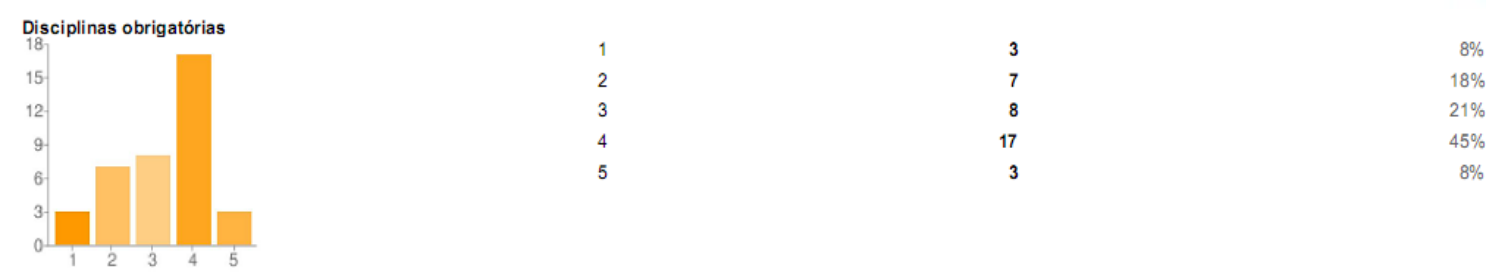

Gráfico 7 - Disciplinas obrigatórias 


\section{ADMINISTRAÇÃO DE EMPRESAS EM REVISTA}

O décimo item, conforme Gráfico 8 referente às disciplinas optativas do curso, aponta que a percepção acerca da insatisfação dos respondentes (avaliação como ruim ou muito ruim) foi de $26 \%$, mantando o patamar dos item anteriores. O percentual daqueles que consideraram o programa muito bom ou bom foi de $42 \%$.

Disciplinas optativas
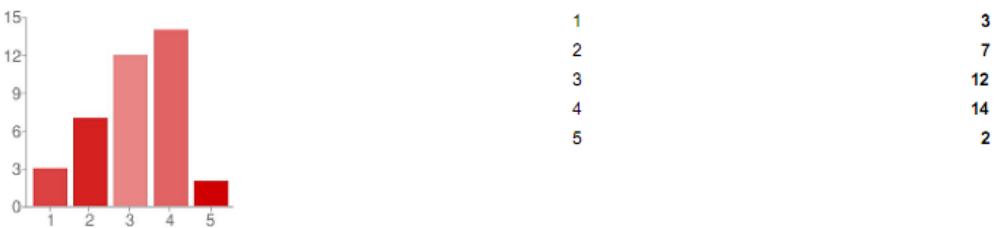

Gráfico 8 - Disciplinas optativas

A avaliação do corpo docente é objeto do décimo primeiro item, representado pelo Gráfico 9. Foi identificado que houve o aumento de $3 \%$ daqueles respondentes que consideram o programa ruim ou muito ruim quando comparado aos itens anteriores. O percentual daqueles que avaliaram o programa como bom ou muito bom manteve-se em $42 \%$.

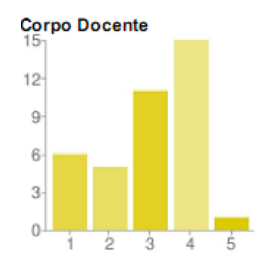

Gráfico 9 - Corpo docente

A abordagem investigativa do décimo segundo item conforme Gráfico 10 referente à infraestrutura do curso aponta que 5\% dos respondentes consideraram o programa muito ruim; $45 \%$ dos respondentes foram indiferentes; $32 \%$ consideraram bom e $18 \%$ avaliaram como muito bom.
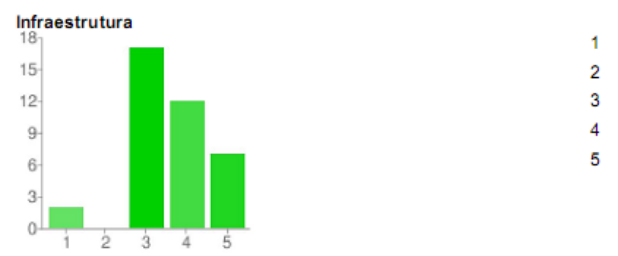

Gráfico 10 - Infraestrutura 


\section{ADMINISTRAÇÃO DE EMPRESAS EM REVISTA}

A avaliação do estágio-docente é objeto do décimo terceiro item, conforme Gráfico 11. Foi identificado que $26 \%$ dos respondentes avaliaram como muito ruim; $16 \%$ como ruim; $18 \%$ foram diferentes; $18 \%$ consideraram como bom e $21 \%$ como muito bom.

Apesar de o estágio-docente na graduação de Ciências Contábeis da UERJ ser um diferencial do Programa, esse quesito não teve uma avaliação satisfatória: $42 \%$ dos respondentes avaliaram como ruim ou muito ruim.

Se somar esse percentual aos $18 \%$ que se colocaram como indiferentes ao estágio chegar-se-á ao total de $60 \%$, um percentual elevado acerca da percepção dos egressos em relação a essa atividade.

Dessa forma, pode-se inferir que o estágio-docente realizado pelos mestrandos do Programa carece de uma reavaliação em função do resultado apresentado. Acredita-se que uma adequada orientação pedagógica deve se fazer presente a fim de identificar, tempestivamente, as aflições, inseguranças e questionamentos dos mestrandos.

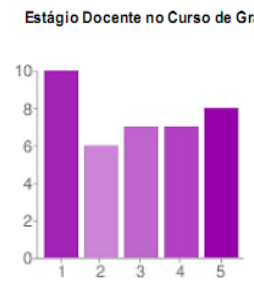

Gráfico 11 - Estágio docente

\subsection{Objetivos do Curso}

O décimo quarto item representado pelo Gráfico 12 referente à capacidade de realização de pesquisas e análises em âmbito local ou regional após o curso indica que $63 \%$ dos respondentes se consideraram (totalmente ou parcialmente) aptos a realizarem pesquisas e análises contábeis em âmbito local e regional. 


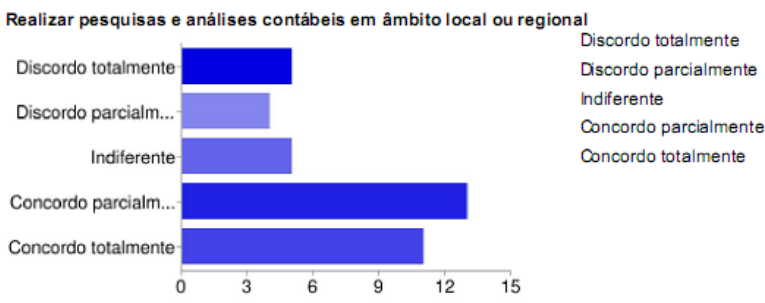

Gráfico 12 - Pesquisas e análises contábeis em âmbito local ou regional

A capacidade de realização de pesquisas e análises em âmbito nacional ao final do curso é objeto do décimo quinto item, conforme Gráfico 13. Foi identificado que $63 \%$ dos respondentes concordaram (totalmente ou parcialmente) que possuíam capacidade para realizar pesquisas e análises contábeis em âmbito nacional. Indiferentes correspondem a $8 \%$, enquanto 29\% discordaram (totalmente ou parcialmente) acerca da aptidão para a realização de pesquisas e análises desse porte.

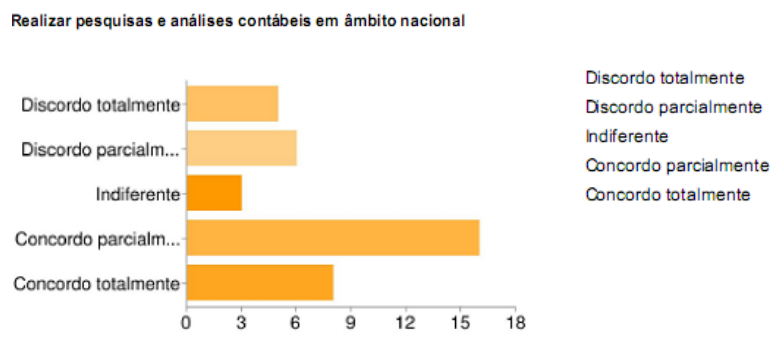

Gráfico 13 - Pesquisas e análises contábeis em âmbito nacional

O décimo sexto item, representado pelo Gráfico 14 referente à capacidade para atuação na área educacional após o curso, aponta que $71 \%$ dos respondentes concordaram (totalmente ou parcialmente) que estão capacitados para atuar na atividade educacional; $3 \%$ mantiveram-se indiferentes, enquanto $26 \%$ discordaram (parcialmente ou totalmente) acerca da capacidade para atuação na área educacional.
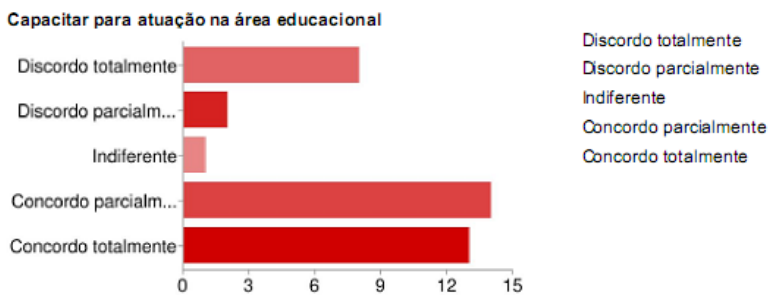

Gráfico 14 - Capacitar para atuação na área educacional 


\subsection{Avaliação descritiva}

O atendimento das expectativas dos entrevistados é objeto do décimo sétimo item, conforme Gráfico 15. Identifica-se que 74\% dos respondentes concordaram (totalmente ou parcialmente) que o PPGCC atendeu as expectativas.

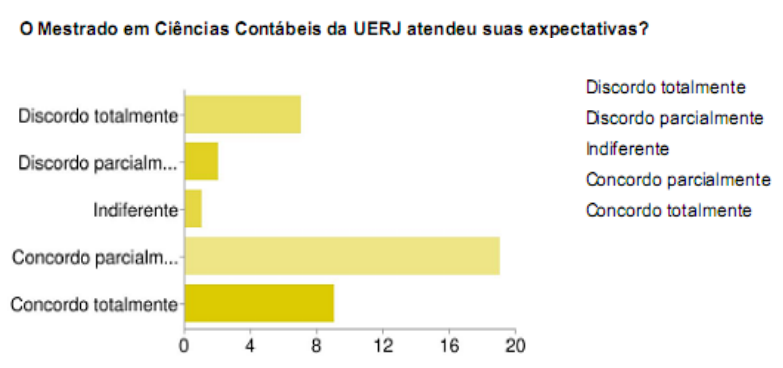

Gráfico 15 - Expectativas

O décimo oitavo item, representado pelo Gráfico 16 referente à formação crítica dos entrevistados, indica que na opinião de $74 \%$ dos respondentes que concordaram (totalmente ou parcialmente), o PPGCC contribui para sua formação enquanto cidadão de tal forma que eles se sentem preparados e com competências para agir proativamente de maneira afirmativa nos ambientes sociais que o cercam. Esse resultado corrobora o papel de um Programa de Pós-graduação na formação do cidadão.

Pode-se inferir que a troca de experiências, os conhecimentos adquiridos ou consolidados e o aprendizado sobre a forma de análise crítica tenham contribuído para que o mestrando desenvolvesse um olhar crítico sobre a realidade ao seu redor.

Um pouco mais de 1/4 (26\%) dos respondentes manifestaram-se indiferentes ou discordaram (parcialmente ou totalmente) sobre esse tipo de contribuição do PPGCC. O resultado de 74\% vem a corroborar o papel de um Programa de PósGraduação na formação do cidadão.

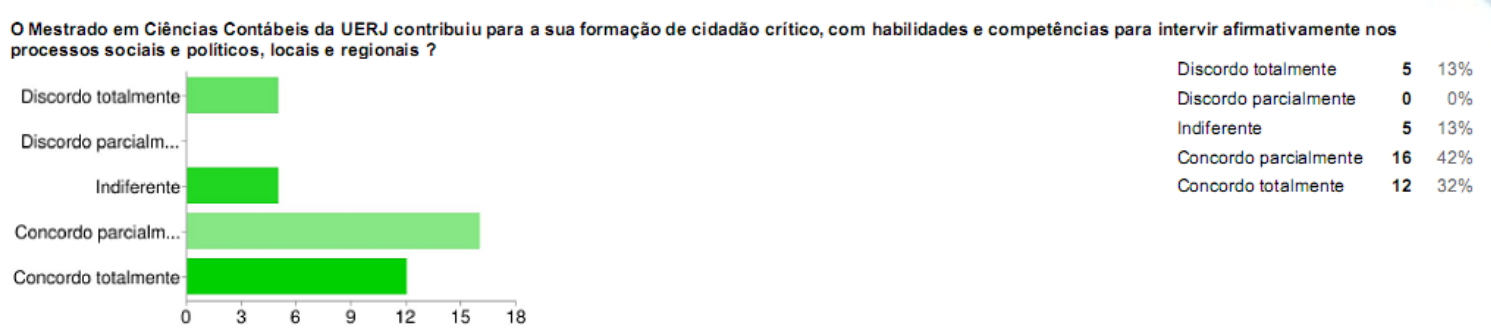




\section{ADMINISTRAÇÃO DE EMPRESAS EM REVISTA}

Gráfico 16 - Formação crítica

A prática profissional é objeto do décimo nono item, conforme Gráfico 17. 0 predomínio da Contabilidade como área de formação dos egressos é notório, visto que esse fato reflete-se na análise desse dado, isto é, $71 \%$ dos respondentes concordaram (totalmente ou parcialmente) a respeito da contribuição do Mestrado para o fortalecimento das suas práticas profissionais.

Um pouco menos de $1 / 3$ dos respondentes mantiveram-se indiferentes ou discordaram (totalmente ou parcialmente) sobre as contribuições do Programa para o fortalecimento das suas práticas profissionais.

O percentual de $71 \%$ indica que, ao final do trabalho desenvolvido, ensinamentos e boas práticas foram levados da Academia para as entidades públicas ou privadas que acolheram esses egressos, que desempenharam o importante papel de disseminadores do conhecimento para a coletividade.
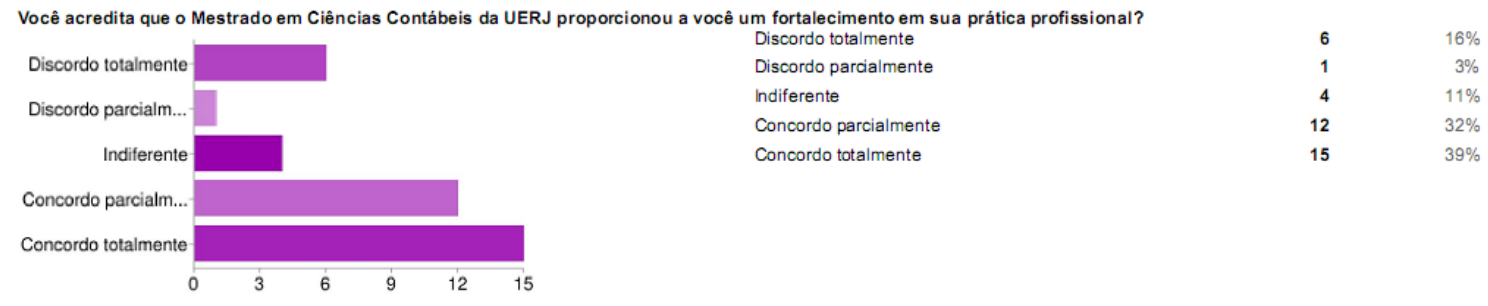

Gráfico 17 - Práticas profissionais

O vigésimo item, representado pelo Gráfico 18 referente à capacitação profissional dos entrevistados, indica que 66\% dos egressos concordam (totalmente ou parcialmente) que o Mestrado incentivou a busca de novas formas de capacitação profissional; $11 \%$ permaneceram indiferentes, ao passo que $23 \%$ dos respondentes discordaram (totalmente ou parcialmente).

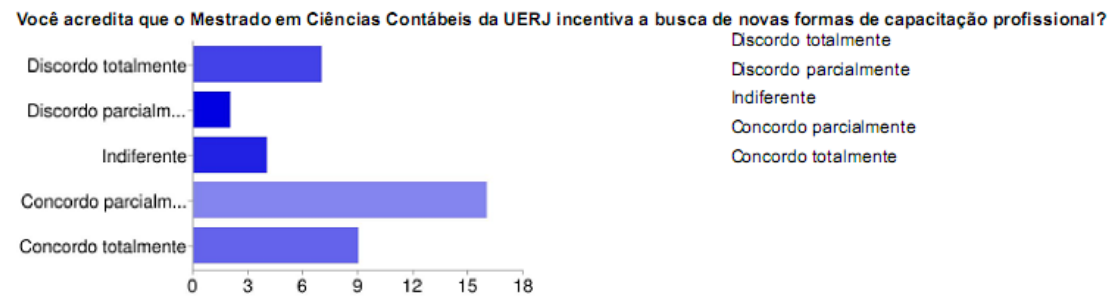

Gráfico 18 - Capacitação profissional 


\section{ADMINISTRAÇÃO DE EMPRESAS EM REVISTA}

A capacitação para a docência é objeto do vigésimo primeiro item, conforme Gráfico 19. Os resultados indicam que $56 \%$ dos egressos concordam (totalmente ou parcialmente) que o estágio docente desenvolvido no Programa contribuiu para a capacitação desses respondentes como professor. Existe uma dicotomia entre esse resultado e aquele apontado pelo Gráfico 10, que apontou que 60\% dos respondentes consideraram a experiência do estágio docente muito ruim, ruim ou indiferente.

Essa dicotomia entre os resultados não permite aos autores inferirem sobre as possíveis causas, uma vez que se verifica uma redução de $15 \%$ entre o mesmo grupo de respondentes (discordam totalmente, parcialmente e indiferente) nos dois gráficos em questão.

Aqueles que se manifestaram de forma indiferente representaram $16 \%$, enquanto $29 \%$ discordaram (totalmente ou parcialmente) acerca da contribuição do estágio docente para a capacitação como professor.

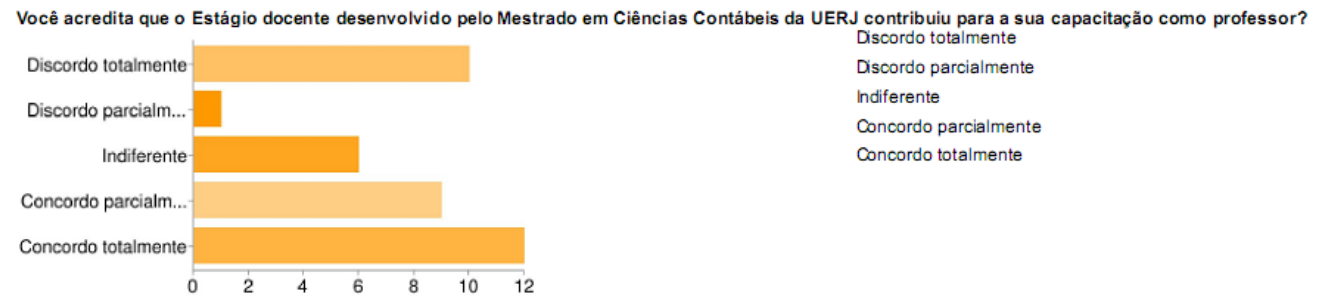

Gráfico 19 - Capacitação para docência

\section{CONCLUSÃO}

Os resultados encontrados e ensinamentos obtidos não podem ser transportados integralmente para outros programas, uma vez que estão afetos a realidades e características distintas do Mestrado conduzido na UERJ. A contribuição à comunidade acadêmica a qual compõem os demais Programas está na metodologia empregada para a prospecção das informações.

O conhecimento dos atores envolvidos no processo é primordial ao traçado do perfil e da percepção dos egressos de um determinado Programa, contribuindo para a identificação das suas deficiências e das potencialidades. Dessa forma, melhora-se o desempenho do programa, produzindo reflexos positivos na formação acadêmica do futuro Mestre, que, ao final de vinte e quatro meses de jornada intermitente, estará apto a ofertar um serviço de mais alto nível à sociedade. 


\section{ADMINISTRAÇÃO DE EMPRESAS EM REVISTA}

O resultado da pesquisa apresentou o seguinte o perfil dos egressos, dentro do universo dos respondentes, considerando-se a divisão das perguntas em três níveis.

O resultado observado em relação à idade atual dos egressos demonstra que $83 \%$ dos respondentes estão na faixa etária compreendida entre 26 e 45 anos, período da vida profissional em que o egresso transita da fase inicial para maturidade profissional, onde os conhecimentos adquiridos ou consolidados poderão ajudá-los para ascensão em suas carreiras. Constata-se um predomínio do sexo masculino (68\%) entre os egressos, embora o Balanço Socioambiental de 2010 do CFC indique um crescimento da participação na atividade contábil, em se tratando de registros ativos. A dedicação ao curso não foi um fator que gerasse um reflexo nas relações conjugais dos egressos ao ponto de desfazê-las, uma vez que a variação apresentada no estado civil dos respondentes (antes, durante e depois da conclusão) foi insignificante.

As respostas correspondentes ao grupo de informações profissionais revelam que $89 \%$ dos respondentes são graduados no curso de Ciências Contábeis, entretanto a turma de 2011 apresente uma maior heterogeneidade entre os cursos de formação superior dos mestrandos; a análise sobre esse dado pode contribuir para que a Coordenação do Curso aperfeiçoe as etapas de futuros processos seletivos a fim de obter o perfil de formação acadêmico-profissional mais adequado às características do Programa.

No que diz respeito à atuação profissional, verifica-se que $47 \%$ dos egressos são oriundos setor público, o que ratifica a relevância do Programa para esse segmento e a natural demanda pelos profissionais da área pública e que $32 \%$ exercem suas atividades no setor público e privado concomitante com prática docente.

Outro dado que deve ser destacado é que após a conclusão do curso, 50\% dos respondentes passaram a ter mais de um vínculo empregatício, esse dado demonstra o impacto que o curso proporciona à vida profissional do egresso.

O grupo de perguntas que trata das percepções dos egressos analisado foi analisado conforme exposto abaixo.

A avaliação geral do Programa revela que os egressos responderam de forma satisfatória aos seguintes itens, considerando-os dentro da escala muito bom (5) e 
bom (4): currículo do curso (63\%), carga horária (65\%), disciplinas obrigatórias (53\%), disciplinas optativas (42\%), corpo docente (42\%) e infraestrutura (50\%).

A observação que pode ser analisada de forma mais criteriosa é a percepção do egresso sobre o estágio docente, visto que há uma quase equivalência sobre os percentuais nas escalas muito ruim e ruim, muito bom e bom; enquanto os últimos representam $39 \%$, os primeiros somam $42 \%$. Esse resultado pode promover uma investigação sobre as principais razões que levaram a esse considerável percentual.

Os objetivos do curso abordaram questões que tratam da realização de pesquisas e análises contábeis em âmbito local ou regional e nacional, e sobre a capacitação para atuação na área educacional. Os egressos responderam com relevantes percentuais, acima de $60 \%$, para concordo totalmente e concordo parcialmente, referente à avaliação sobre esses itens. Esse dado permite inferir que o aprendizado tem levado o egresso a um raciocínio crítico que o permite analisar questões contábeis e o estimula a realizar pesquisas. Outra constatação a ser considerada é que o egresso se sente capacitado para atuar na área educacional.

No que tange à avaliação descritiva sobre o Programa, 74\% dos respondentes informaram que o curso atendeu as suas expectativas; $64 \%$ que o mestrado contribuiu na sua formação como cidadão crítico a ponto de intervir afirmativamente nos processos sociais e políticos, locais e regionais; $71 \%$ entenderam o curso proporcionou um fortalecimento nas práticas profissionais dos egressos; $66 \%$ se sentiram incentivados pelo mestrado a buscar novas formas de capacitação profissional; e 56\% acreditam que o estágio docente desenvolvido, no curso de graduação em Ciências Contábeis da UERJ, contribuiu para a capacitação dos egressos como professores. Esses percentuais representam a soma das opções respostas (concordo totalmente e concordo parcialmente).

Pesquisas dessa natureza representam uma contribuição do aluno a Instituições de Ensino que o acolheu e possibilita que, com conhecimento corporificado em artigo científico, haja a otimização dos recursos disponíveis e eventuais correções de rumo do Programa, face à identificação de novas tendências.

O "artigo científico", para Shellis [apud Filho, 2011], nada mais é do que uma "forma de devolver à sociedade parte daquilo que ela ajudou a produzir"; trata-se de uma prestação de contas à sociedade Fluminense pelo investimento no Programa de 
Mestrado em Ciências Contábeis ao longo dos últimos 20 anos, idéia resumida na frase "avaliar para melhor ensinar e formar".

\section{REFERÊNCIAS}

ASSOCIAÇÃO NACIONAL DOS PROGRAMAS DE PÓS-GRADUAÇÃO EM CONTABILIDADE - ANPCONT. Mestres e Doutores Titulados. Disponível em: <http://anpcont.com.br/site/docs/mestdoutanpcont.pdf>. Acesso em: 09 ago. 2011. CONSELHO FEDERAL DE CONTABILIDADE - CFC. Balanço Socioambiental 2010. Disponível em: < http://www.cfc.org.br/uparq/bs_2010.pdf>. Acesso em: 07 ago. 2011. DUARTE, E. N. et al. Estratégias metodológicas adotadas nas pesquisas de iniciação científica premiadas na UFPB. Encontros Bibli (UFSC), 2009. Disponível em: <http://www.periodicos.ufsc.br/index.php/eb/article/view/6130/10143>. Acesso em: 09 ago. 2011.

FERNANDES, A. M. et al. O Programa de Mestrado em Contabilidade da UERJ. Disp. em:<http://www.sergiomariz.com/mcc.uerj/index2.php?option=com_docman\&task=d oc_view\&gid=127\&Itemid=51>. Acesso em: 08 ago. 2011.

FILHO, M. A. Para Peter Shellis, artigos científicos dão retorno à sociedade. Portal UNICAMP, Campinas, 14 abr. 2011, p. 1-3. Disponível em: <http://www.unicamp.br/unicamp/divulgacao/2011/04/15/para-robert-shellis-artigoscientificos-dao-retorno-a-sociedade>. Acesso em: 08 ago. 2011 MAGALHÃES, E. A. et al. Apuração do Custo por Aluno do Ensino de Graduação da Universidade Federal de Viçosa. In: XXXI Encontro da ANPAD - EnANPAD, 2007, Rio de Janeiro. XXXI Encontro da ANPAD - EnANPAD. Rio de Janeiro, 2007.

MARTINS, O. S; MONTE, P. A. Determinantes da variação salarial dos Mestres em Ciências Contábeis. In: ANPCONT, 4., 2010, Natal. EPC163. Natal: ANPCONT, 2010. PELEIAS, I. R. et al. Evolução do Ensino de Contabilidade no Brasil: uma análise histórica. Revista de Contabilidade e Finanças, São Paulo, p.19-32, jun. 2007.

RAMOS, F. R. S. et al. Formação de mestres em enfermagem na Universidade Federal de Santa Catarina: contribuições sob a ótica de egressos. Revista Brasileira de Enfermagem, Brasilia, p.63-63, jun. 2010.

SÁ, D. T.; SIQUEIRA, V. H. F.; MARTELETO, M. A. Demanda e clientela multiprofissional: influências e desafios para um Mestrado em Tecnologia Educacional 


\section{ADMINISTRAÇÃO DE EMPRESAS EM REVISTA}

CENTRO UNIVERSITÁRIO CURITIBA - UNICURITIBA - VOLUME 19 - NÚMERO 01/2019 -CURITIBA/PARANÁ/BRASIL - PÁGINAS 148 A 169 - DOI: 10.6084/m9.figshare.11338469- ISSN: 2316-7548

nas Ciências da Saúde. Cad. Saúde Pública, Rio de Janeiro, n. 15(Sup. 2), p.45-53, 1999.

SILVA, A. L. R. Da substituição de importações a substituição de exportações. Revista Brasileira de Política Internacional, vol.48, n.2, p. 218-220, 2005.

SPINK, P. K. A Formação Acadêmica e a Ciência: Ampliando o Debate sobre o Mestrado Profissional. RAC. Revista de Administração Contemporânea, v. 1, p. 163169, 1997.

VIEIRA, S. S. C. Avaliação de programas de educação continuada: análise da percepção do aluno e do seu modelo de decisão para escolha de programas de especialização para executivos no Brasil. 2009. 1 v. Tese (Doutorado) - Curso de Controladoria e Contabilidade, Departamento da FEA, USP, São Paulo, 2009. 